Anuario de

Derechos Humanos 2005 


\title{
Juzgados de Familia y Derechos Humanos
}

\author{
Alejandra Riveros ${ }^{*}$ \\ Alberto Cerda Silva**
}

\section{La Ley 19.968 que crea los Tribunales de Familia}

L a nueva Ley de Tribunales de Familia, que entrará en vigencia en octubre de este año, se enmarca dentro de un conjunto de iniciativas de modernización del Estado en el área de justicia, tales como la entrada en vigencia de la reforma procesal penal, el fomento del uso de sistemas alternativos al jurisdiccional para la resolución de los conflictos y una mejora sustancial en los programas de acceso a la justicia para los sectores más marginados del sistema jurisdiccional.

La nueva ley tiene como objetivo central dotar a nuestro sistema de administración de justicia, de órganos y procedimientos para hacer frente a un especial tipo de conflicto, para el cual, hasta hoy, nuestro ordenamiento carece de una respuesta específica: el de naturaleza familiar.

La justicia de familia y de menores que hoy se modifica, posee una inspiración conceptual y un diseño procedimental que no se condice ni con la especial naturaleza compleja y sistémica del conflicto familiar, ni con las exigencias del Derecho Internacional de los Derechos Humanos; por ello la necesidad de relevar la calidad de sujetos de derechos de los niños(as) en el sistema juridiccional, y la necesidad de que éstos sea oídos en un proceso interactivo, donde sus intereses sean especialmente considerados.

Por ende, la nueva justicia de familia que próximamente empezará a operar constituye la respuesta lógica en el ámbito procesal para dar cabal cumplimiento al deber del Estado de proteger la familia, según lo consagrado a nivel constitucional y en los múltiples instrumentos internacionales sobre derechos humanos suscritos y ratificados por Chile.

La reforma al sistema de administración de justicia en materia de familia tiene por objeto instalar un nuevo paradigma en la forma de resolver los conflictos de familia, modificando el carácter predominantemente adversarial, eliminando las prácticas de intermediación funcionaria, así como la alta discrecionalidad judicial. En su lugar se propone una justicia de familia con jurisdicción única y especializada donde primarán los principios de celeridad e inmediación, así como la promoción de soluciones consensuadas acordes con el tipo de conflicto que se ventile.

En cuanto a su conformación, los juzgados estarán compuestos por un número variable de jueces - de uno a doce-, si bien ejercerán su función

\footnotetext{
* Abogada, Universidad de Chile, Magíster en Políticas Públicas, Administración y Gestión (c) Universidad de Chile, Asesora del Departamento de Menores del Ministerio de Justicia.

** Profesor Asistente de Derecho Informático, Facultad de Derecho, Universidad de Chile.
}

Este comentario, junto con el documento principal a que se refiere, están disponibles en formato digital en www.anuariocdh.uchile.cl 
jurisdiccional individualmente; el nuevo sistema contempla 60 juzgados especializados en conflictos de Familia e Infancia, que en total suman 268 jueces. Contarán además con un administrador y una planta de empleados, que deberán cumplir las funciones de atención a público, servicios, administración de causas y sala. Adicionalmente, en tales Juzgados de Familia y en los 77 Juzgados de Letras con competencia en asuntos de familia, habrá un Consejo Técnico, integrado por un número variable de profesionales -de uno a doce- especializados en asuntos de familia e infancia, cuya función será asesorar individual o colectivamente a los jueces, en el análisis y mejor comprensión de los asuntos sometidos a su conocimiento, en el ámbito de su especialidad.

Las materias de competencia de los juzgados de familia serán: el cuidado personal de los niños, niñas o adolescentes; la regulación del régimen comunicacional con los hijos; la patria potestad; los alimentos; los disensos para contraer matrimonio; las guardas en general; la resolución sobre la vida futura del niño, niña o adolescente, en determinados casos; los asuntos en que aparezcan éstos gravemente vulnerados o amenazados en sus derechos; las acciones de filiación; la citación a confesar paternidad o maternidad; los asuntos en que se impute un hecho punible a niños, niñas o adolescentes exentos de responsabilidad penal; la autorización para la salida de niños del país; los procedimientos previos a la adopción; la adopción propiamente tal; lo relativo al régimen patrimonial del matrimonio y los bienes familiares; la separación judicial, la nulidad y el divorcio; las declaraciones de interdicción; los actos de violencia intrafamiliar y maltrato infantil; $y$, en general, toda otra cuestión personal derivada de las relaciones de familia.

Como principios fundamentales del nuevo sistema, se consagran expresamente el principio de oralidad, desformalización, concentración, inmediación, actuación de oficio, colaboración, protección a la intimidad e interés superior del niño, niña o adolescente y su derecho a ser oído. Sobre éstos, cabe decir que serán determinantes en materia de interpretación e integración de la ley, en caso de vacíos o contradicciones legales.

Por último, sobre el procedimiento propiamente tal, la ley se estructura en base a un procedimiento ordinario y dos procedimientos especiales: el de aplicación de medidas de protección tendientes a proteger los derechos de los niños, niñas y adolescentes cuando éstos se encuentran amenazados o vulnerados, y el de violencia intrafamiliar. No obstante, la ley hace también una breve alusión a la tramitación de asuntos no contenciosos y modifica parcialmente los trámites de adopción de niños, a fin de adecuarlos a los principios que informan la nueva administración de justicia en asuntos de familia.

\section{Análisis con Perspectiva de Derechos Humanos}

La ley que instituye los Juzgados de Familia evidencia a lo largo de su texto la recepción de los derechos humanos, tal como ellos se han 
esbozado en los diversos instrumentos internacionales sobre la materia y en nuestra Carta Fundamental. Sin embargo, tratándose de algunos de ellos, ha ido aún más allá.

En efecto, desde sus primeras disposiciones se aprecia especial celo en el derecho a la intimidad, especialmente de los niños, niñas y adolescentes, en la protección de los datos personales e imagen de las partes litigantes; otro tanto acontece con el interés superior del niño, y su derecho a ser oído, principios rectores que el juez de familia debe tener siempre como consideración principal en la resolución del asunto sometido a su conocimiento. Igual énfasis se observa en la exclusión de pruebas cuando ellas han sido obtenidas con infracción de garantías fundamentales, tales como el derecho de propiedad, el respeto y protección de la vida privada y pública y la honra de la persona y su familia, así como la inviolabilidad del hogar y de toda forma de comunicación privada.

Sin embargo, dos aristas de la ley asociadas con los derechos humanos nos merecen especial relevancia, tanto por el giro copernicano que importan respecto de la administración de justicia en asuntos de familia en relación con el modelo actual, como por la naturaleza de los conflictos Ilamados a conocer por los nuevos tribunales; nos referimos a las perspectivas de acceso a la justicia y de género.

\section{II.a. Acceso a la Justicia}

El derecho a un efectivo acceso a la justicia debe considerarse como un derecho humano de importancia primordial, por lo que aliviar la incapacidad de muchas personas para hacer cabal uso de la ley y de sus instituciones debe ser una de las preocupaciones del poder público: la expresión "acceso a la justicia" no representa la sola oportunidad para emprender acciones judiciales, sino asegurar a todos y cada uno de quienes forman parte del cuerpo social la disposición equitativa de las condiciones necesarias para ejercer en forma efectiva sus libertades y derechos.

Un acceso a la justicia en las condiciones antes referidas contribuye a la democratización y a la institucionalización y redefinición de la relación entre la Sociedad y el Estado, garantizando la legitimidad ante la ciudadanía del andamiaje estatal.

El acceso a la justicia ha sido asimilado a la garantía de las personas para ejercer acciones judiciales, el llamado derecho a la jurisdicción, en otros términos, el derecho a acudir a los Tribunales de Justicia para obtener la resolución de las controversias de relevancia jurídica. Sin embargo, el acceso a la justicia es más que la posibilidad de acudir a tribunales, es también una obligación para el Estado, según lo sostenido por Mauro Cappelletti, a efectos de generar las condiciones adecuadas para concretizar tal derecho.

En efecto, asumir que todos los justiciables podían llevar sus diferencias hasta ante los Tribunales, y que éstos, a su vez, estaban en condiciones 
de responder apropiadamente ante una avalancha tal, obviaba la existencia de obstáculos económicos, jurídicos, sociales y culturales asociados al efectivo ejercicio de tal derecho, los cuales ciertamente era necesario remover no sólo porque entraban el acceso de los ciudadanos a la solución de sus diferencias jurídicas, sino porque deslegitiman el accionar del Estado.

Mediante la Ley que crea los Juzgados de Familia, el Estado ha impulsado y concretizado su afán modernizador de la administración de justicia en asuntos de familia, ensanchando el alcance conceptual del acceso a la justicia, al comprender:

a) La ampliación de la asistencia jurídica más allá de la representación judicial, incluyendo la información, orientación y alfabetización jurídica, imponiendo cometidos precisos al respecto inclusive a los propios tribunales de justicia, desde la interposición oral de demandas, hasta la ilustración del sentido y alcance de la mediación familiar, y la institución de una unidad especializada de atención de público en cada uno de los tribunales.

b) La revisión de los procedimientos, mediante la institución de los principios de oralidad e inmediación, junto con optarse por la concentración sustancial de las actuaciones en dos audiencias: una audiencia preparatoria, en la cual tiene lugar la discusión entre las partes, se promueven la mediación y conciliación, se delimita el objeto del juicio y determinan las pruebas a ser rendidas, entre otros cometidos; $y$, una segunda audiencia, propiamente de juicio, en la cual el tribunal recibe la prueba, escucha las alegaciones de las partes y dicta sentencia.

c) La revisión de las competencias, desde que la mayoría de los conflictos que se generan en relación a niños, niñas y adolescentes están relacionados directamente con el entorno, historia y vivencias en las que se sitúan. Hasta la fecha, la solución de tales causas requerían la intervención de diversos tribunales y la tramitación previa de diversos procedimientos, algunos de ellos coexistentes, en los que, ocasionalmente, se adoptaban decisiones contradictorias. La ley innova procurando evitar la situación recién anotada en nuestra administración de justicia en materias de familia, al permitir que todas las cuestiones concernientes a niños, niñas, adolescentes, cónyuges y patrimonio, que existan en un contexto familiar, sean conocidas por un mismo tribunal y hasta en un mismo procedimiento; de ahí que las materias que hasta la fecha conocían los Juzgados de Letras de Menores sean radicadas en los Juzgados de Familia, los que, de otra parte, absorben asuntos cuya competencia se encontraba antes radicada en Juzgados de Letras en lo Civil.

d) El diseño administrativo de tribunales, desde que la estructura y las funciones de los nuevos Juzgados de Familia ha seguido muy de cerca las previsiones de los Tribunales que forman parte de la reforma procesal penal, al extremo de hacer aplicables, en cuanto 
resulten compatibles, las normas previstas para los juzgados de garantía y tribunales de juicio oral en lo penal en relación a comité de jueces, juez presidente, administradores de tribunales y organización administrativa de los juzgados. En efecto, a un número variable de jueces -que oscila entre 1 y 12 magistrados-se agregan un Comité de Jueces, presidido por un Juez Presidente, un administrador y una planta de empleados u oficiales de secretaría que se organizan en diversas unidades administrativas para el cumplimiento eficaz y eficiente de sus funciones. Además, la ley contempla una institución nueva en el marco de nuestra administración de justicia: el Consejo Técnico, el que ha de brindar la asistencia técnica necesaria para la adecuada conducción y resolución de las controversias de naturaleza familiar.

e) La diversificación de los medios de resolución de conflictos, privilegiando la solución alternativa de ellos y reservando la intervención estatal para aquéllos en que resulta imposible avenir los intereses en discordia o en que aparecen afectados bienes jurídicos de mayor valor. Se trata de alentar una justicia que, al decir de Mirjan Damaska, se centra en la resolución de las controversias y, marginalmente, en la imposición de políticas públicas, como no se trate de la solución de las diferencias de relevancia jurídica. Al efecto, la ley ha alentado la resolución de controversias mediante la conciliación judicial, en la que el juez propone a las partes bases de solución y, a su vez, ha instituido un sistema de mediación familiar, en que profesionales calificados las asisten en la resolución de sus diferencias, al cual las partes pueden ser derivadas voluntariamente desde el instante mismo de la interposición de la demanda.

f) La eliminación de trabas normativas que, bajo las restricciones propias de una atávica reglamentación procesal, impiden el acceso a la justicia o desvirtúan los efectos de los institutos procesales. Así se observa en la desformalización del procedimiento, la simplificación del sistema de notificaciones, la concesión de facultades al juez para enmendar actuaciones judiciales, sin perjuicio de los recursos procesales, y la posibilidad de que las partes litiguen personalmente ante el tribunal.

Así pues, debe reconocerse y valorarse el esfuerzo legislativo por rebasar el alcance conceptual del acceso a la justicia como el mero derecho a acudir en pos de la resolución judicial de un conflicto, para incluir bajo su entendido la revisión de competencias, procedimientos y estructura administrativa de nuestros tribunales, a la par de alentar una asistencia jurídica más integral, prescindir de trabas procesales obsoletas y diversificar las fórmulas de solución de los asuntos de familia. 


\section{II.b. Perspectiva de género}

La satisfacción de las necesidades de asistencia jurídica gratuita de la ciudadanía constituye un factor estabilizador de la sociedad, que contribuye a la sana convivencia social, a la estabilidad política y al desarrollo económico; la agenda pública, en este aspecto, se ha visto marcada por la convicción de que "la indefensión constituye uno de los rostros más dramáticos de la pobreza". De ahí que sea necesario restablecer el equilibrio que garantice efectivamente la igualdad de todos los habitantes de la República, labor que desempeñan preferentemente las instituciones de asistencia jurídica gratuita.

Desde una perspectiva de género, el tema no es menor, sobre todo si consideramos que las mujeres son las principales usuarias del sistema judicial, especialmente en asuntos de familia. Las estadísticas judiciales confirman que la mayor demanda está constituida por juicios por pensión alimenticia, los que corresponden a más del $50 \%$ de los procesos Ilevados actualmente ante los Tribunales de Menores. Lo propio acontece con la composición de los usuarios del Sistema Gratuito de Acceso a la Justicia, desde que, según Informe Estadístico 2004 de la División Judicial del Ministerio de Justicia, un 70\% de ellos pertenece al sexo femenino. Esto nos llama a analizar la nueva normativa sobre administración de justicia en asuntos de familia desde la especial naturaleza de los asuntos que les tocará resolver a los nuevos tribunales.

El conflicto familiar, dada su naturaleza, no permite ser sustraído del contexto económico, social y cultural que Ileva implícito, cualquiera sea el nivel socioeconómico de las partes involucradas. En este sentido, una mirada de género es especialmente oportuna, a la luz de la diversidad de conflictos que hombres y mujeres enfrentan a diario en el plano familiar.

El análisis de género identifica cómo las políticas afectan a hombres y mujeres. En algunos casos las diferencias entre ambos pueden ser significativas e incidir tanto en la aplicación de la normativa como en el diseño de políticas públicas, lo que implicará considerar y respetar la diversidad; ya que si tratamos a hombres y mujeres por igual se pasarán por alto las experiencias de vida de cada cual en particular.

En el plano normativo, nos parece oportuno reparar en la presencia de ciertas opciones carentes de neutralidad, sin perjuicio de cuanto resulte de su aplicación por los organismos públicos, sean administrativos o judiciales. Ellas están asociadas a la asistencia letrada en juicio, a la extensión conceptual de familia a efectos de la competencia judicial y al haz de medios disponibles para enfrentar la violencia intrafamiliar.

La ley admite la comparecencia personal de las partes ante tribunales, prescindiendo de la asistencia letrada al efecto; no obstante, el juez podrá ordenar la asesoría de abogado, cuando lo estime necesario, especialmente en aquellos casos en que una de las partes cuente con tal 
asesoría, y tratándose de los asuntos en que aparezcan involucrados intereses de niños, niñas, adolescentes, o incapaces, y éstos carezcan de representante legal o cuando, por motivos fundados, el juez estime que sus intereses son independientes o contradictorios con los de aquel a quien corresponda legalmente su representación, evento en que designará a alguno de los servicios de asistencia jurídica gratuita. Sobre el particular nos parece que la ley no garantiza suficientemente la asistencia letrada a las partes comparecientes, sino muy excepcionalmente, lo cual Ilama a reparos, desde que los costos asociados a tal asistencia constituyen una barrera de entrada que repercute principalmente en la parte económicamente más débil, que, en el caso de los conflictos de naturaleza familiar, son los hijos y las mujeres.

Otro tanto acontece con la cláusula general de competencia de los nuevos tribunales, aquélla conforme a la cual éstos serán los Ilamados a conocer y resolver "toda otra cuestión personal derivada de las relaciones de familia". Se trata de una formulación conceptual abierta, que permitirá la actualización de las materias a ser sometidas a estos tribunales, pero su limitación a los asuntos de naturaleza personal, da pie a la exclusión de aquéllas de naturaleza patrimonial derivadas de las relaciones de familia, salvo que una disposición distinta confiera tal competencia, tal como acontece con los asuntos sobre régimen patrimonial del matrimonio. Sin embargo, tal cláusula impediría a estos nuevos tribunales conocer de los conflictos relativos al régimen de bienes que media en las relaciones de convivencia, cuya competencia quedaría radicada ante los Juzgados de Letras en lo Civil, con el consiguiente detrimento en quien no ha desarrollado actividad económicamente lucrativa, situación que, como corroboran las estadísticas, recae mayoritariamente en las mujeres.

También es la situación que se nos presenta en relación a la respuesta institucional que la nueva ley contempla frente a los actos de violencia intrafamiliar. Si bien se introducen mejoras en cuanto al catálogo de medidas de resguardo de la integridad de las víctimas, el divorcio entre los planos normativo y fáctico no garantiza la efectividad de la norma: la precariedad de la red de servicios, sea prestados por organismos públicos o privados, destinados a dar respuestas efectivas y oportunas, particularmente con las víctimas que carecen de adecuadas redes familiares de apoyo, ponen en riesgo de socavar la fiabilidad del sistema, desincentivar la denuncia de tales hechos e incrementar la brecha entre quienes padecen de la violencia doméstica, que, usualmente, corresponde a mujeres.

Así pues, desde una perspectiva de género, si bien la ley representa una mejora respecto del precedente sistema de administración de justicia en asuntos de familia, aún muestra algunos resabios que evidencian la necesidad de restablecer los equilibrios a fin de evitar desigualdades derivadas sustancialmente de la condición de quienes son sus usuarios. 


\section{Conclusiones}

En definitiva, la nueva ley que crea los Juzgados de Familia contribuye a la efectiva modernización de la administración de justicia, concretando la vigencia de los derechos humanos en ella, con una mirada que enfatiza y asegura condiciones de acceso y se hace cargo parcialmente de las diferencias de género, lo cual representa una ostensible mejora respecto del actual sistema.

Sin embargo, la mayor o menor fortuna de las disposiciones normativas estará entregada a la concreción que reciban por los operadores jurídicos, así mediante la automatización de gestión de los tribunales en aras de un uso eficaz de los recursos disponibles, así como en el incremento de aquellos destinados a los organismos públicos que coadyuvan a la adecuada administración de justicia, sea, por mencionar algunos, en la profesionalización de asistencia letrada, aun insuficientemente resguardada, o en la extensión de servicios asociados. 